\title{
Micobiota e determinação de micotoxinas em rações comerciais destinadas para calopsitas (Nynphicus hollandicus) no Rio de Janeiro, Brasil
}

\author{
Felipe Braz Nielsen Köptcke ${ }^{1}$, Nathalia Dutra Knust², Thiago Teixeira Moraes ${ }^{3}$, Marcos Aronovich ${ }^{4}$, Victor Moebus Farias ${ }^{5}$,
} Leonardo de Assunção Pinto ${ }^{1}$, Luiz Antonio Moura Keller ${ }^{6}$

\begin{abstract}
Resumo
Rações comerciais possuem ingredientes que variam de acordo com o valor nutricional que se quer conferir ao produto final e a espécie para qual se destina. Apesar das possibilidades de variações, cereais e grãos são a matéria prima de qualquer ração. Contudo, são altamente susceptíveis às micotoxinas. Considerando a matéria prima como a principal fonte de contaminação fúngica, o objetivo desta proposta foi avaliar a contaminação em potencial por fungos e suas micotoxinas em rações oferecidas para aves ornamentais do gênero Nynphicus hollandicus. Para o presente estudo, foram adquiridas rações de marcas comerciais para o consumo por aves ornamentais. As amostras foram adquiridas ao longo de seis meses, visando a obtenção de lotes diferentes, totalizando 35 amostras de rações ao todo. Para as análises micológicas foram utilizados os meios de cultura DG18, DRBC e DCPA para contagem fúngica e o meio MEA para isolamento e identificação dos fungos encontrados. A determinação de micotoxinas foi realizada através de testes imunoenzimáticos com confirmação por cromatografia líquida de alta eficiência. $O$ resultado da contagem de unidades formadoras de colônias é sugestivo de uma atividade fúngica elevada, já que as amostras apresentaram apenas a contagem de Fusarium spp. dentro do limite preconizado.
\end{abstract}

Palavras-chave: Aspergillus flavus; produção de micotoxinas; rações; aves.

\section{Introdução}

A contaminação fúngica e de micotoxinas em rações é um problema que afeta o agronegócio. As matérias primas utilizadas podem diretamente constituir a ração, ou podem passar por um processo de mistura. Acontaminação pode ocorrer antes, durante ou após o processamento da matéria prima, advinda de diversas fontes de contaminação (processamento, armazenamento e manuseio das matérias primas). Frequentemente a qualidade das matérias primas comercializadas é inferior já que são destinadas à alimentação animal (KELLER et al., 2013).

A criação de diversas marcas de dietas para aves vem com o objetivo de acrescentar qualidade e inovação para alimentar esses animais. A avaliação da qualidade dos ingredientes e uma dieta balanceada são importantes para preservar a saúde desses animais. Considerando conjuntamente a manutenção de suas necessidades nutricionais e demandas básicas (KELLER et al, 2012).

Micotoxinas são metabólitos secundários tóxicos produzidos por fungos que podem causar efeitos nocivos em humanos e animais. As principais micotoxinas de importância agroeconômica e médica são as aflatoxinas (AFLs), ocratoxina A (OTA), zearalenona (ZON) e fumonisinas (FBs) (SCUSSEL et al., 1988).

As AFLs são um grupo de metabólitos secundários tóxicos produzidos por diversas espécies do gênero Aspergillus, destacando-se Aspergillus flavus, Aspergillus parasiticus e Aspergillus nominus. Os fungos produtores de AFLs podem crescer em determinados alimentos e rações, sob circunstâncias favoráveis de temperatura e umidade podendo gerar AFLs antes ou durante a colheita e durante o armazenamento da matéria prima.

Ocratoxinas são metabólitos tóxicos produzidos por diversas espécies de fungos dos gêneros Aspergillus e Penicillium, destacando-se Aspergillus ochraceus e Penicillium verrucosum como principais produtores. Compreendem um grupo de sete compostos dos quais destaca-se a ocratoxina $\mathrm{A}(\mathrm{OTA})$ já que esta, frequentemente é encontrada como contaminante em alimentos. O crescimento e desenvolvimento desses fungos está relacionada ao clima tropical, assim como a produção de OTA e, em aves, os efeitos da OTA são nefrotóxicos e hepatotóxicos (MARTH, 1992).

A zearalenona é uma micotoxina produzida principalmente por espécies do gênero Fusarium, como Fusarium graminearum, $F$. culmorum, F. equiseti F. moniliforme. É uma micotoxina comumente encontrada como contaminante por todo o mundo, presente em diversos tipos de cereais.

As fumonisinas consistem num grupo de substâncias tóxicas produzidas por fungos da espécie Fusarium (moniliforme) verticillioides. Neste grupo estão a fumonisina B1 (FB1), fumonisina B2 (FB2), fumonisina B3 (FB3), fumonisina B4

\footnotetext{
1 Graduando em Farmácia - Faculdade de Farmácia - Universidade Federal Fluminense - Niterói, RJ. - Bolsista de Iniciação Científica pelo Programa Institucional de Bolsas de Iniciação Cientifica da UFF (PIBIC-UFF) - E-mail: felipekoptcke@id.uff.br.

${ }^{2}$ Graduanda em Medicina Veterinária - Faculdade de Veterinária - Universidade Federal Fluminense - Niterói, RJ.

${ }^{3}$ Médico veterinário autônomo.

${ }^{4}$ Pesquisador da Empresa de Pesquisa Agropecuária do Estado do Rio de Janeiro (PESAGRO-RJ) - Niterói, RJ.

${ }^{5}$ Doutorando do curso de Higiene Veterinária e Tecnologia de Produtos de Origem Animal - Faculdade de Veterinária - Universidade Federal Fluminense Niterói, RJ.

${ }^{6}$ Professor do curso de Medicina Veterinária - Faculdade de veterinária - Universidade Federal Fluminense - Niterói, RJ.
} 
(FB4), fumonisina A1 (FA1), fumonisina A2 (FA2) e fumonisina $C$ (FC). Destas destacam-se a FB1, FB2 e FB3 devido à sua alta toxicidade (LEITAO, et al. 2016).

Avaliar a presença de micotoxinas em rações animais é de extrema importância, porque estas podem levar a diversas patologias, principalmente, a oncogênese. O foco desse estudo é avaliar a contaminação em potencial por fungos e suas micotoxinas em rações oferecidas para aves ornamentais.

\section{Materiais e Métodos}

Da amostragem foram consideradas coletas a partir da seleção de marcas comerciais representativas de indicação de consumo por aves da espécie Nymphicus hollandicus, popularmente conhecidas como calopsitas. As amostras foram adquiridas, ao longo de seis meses, para obtenção de lotes diferentes, tendo as embalagens sido acondicionadas e transportadas sob refrigeração. Ao todo foram coletadas 35 amostras de diferentes rações foram obtidas, compreendendo três lotes diferentes.

As amostras foram encaminhadas aos laboratórios do Núcleo de Toxicologia e Sanidade Animal da Universidade Federal Fluminense e Centro de Pesquisa em Alimentos Qualidade de Alimentos do Estado do Rio de Janeiro (CEPQA/PESAGRO-RJ) em até $24 \mathrm{~h}$, onde foram imediatamente processadas para as análises. Para obtenção de sub amostras, todas as embalagens foram abertas de forma asséptica para homogeneização e encaminhando para os protocolos de isolamento da micobiota e detecção de micotoxinas. Os testes analíticos aos quais as amostras foram submetidas foram realizados em triplicata, assim minimizando o viés estatístico.

Todas as amostras foram submetidas à determinação das atividades de água (Aw), utilizado o equipamento AquaLab® modelo cx 2 (Decagon, Devices, Inc. USA).

Para a determinação de micobiota, foi feita a diluição decimal seriada em placas segundo PITT; HOCKING (1997). Posteriormente, inoculou-se em triplicata alíquotas de 0,1 ml de cada uma das diluições em três meios de cultivo: Ágar Dicloran Glicerol (DG18) que é um meio de cultura recomendado para amostras com baixa atividade de água permitindo o crescimento de fungos xerofílicos, aqueles que suportam baixa aw, sem reduzir ou limitar seu crescimento. Todas as amostras analisadas apresentaram contagens média a altas neste meio, demostrando a possibilidade de risco a saúde, já que entre os xerofílicos estão incluídos dois dos principais gêneros toxígenos, Aspergillus e Penicillium para fungos xerófilos (PITT, 1997); meio Dicloran Rosa de Bengala Cloranfenicol Ágar (DRBC) é utilizado em alimentos com aw maior que 0,95 , em alimentos com baixa aw (como no caso de rações) pode ser utilizado para estimar o total de fungos não xerófilos, já que pode inibir o crescimento dos mesmos e Ágar Dichloran Cloranfenicol Peptona (DCPA) para fungos do gênero Fusarium (NELSON et al., 1983). As placas foram incubadas a $25^{\circ} \mathrm{C}$ por sete dias. Durante o quinto até o sétimo dia de incubação, foram selecionadas algumas cepas para identificação específica e contagem de propágulos fúngicos para enumeração quantitativa em unidades formadoras de colônias por grama de amostra (10 a 100 UFC g-1). Posteriormente ao isolamento específico, as cepas, incubadas em meio Ágar Extrato de Malte (MEA), foram avaliadas com base nas características macro e microscópicas e identificadas segundo as chaves taxonômicas, com o auxílio de microscópio com base na literatura (NELSON et al., 1983 para Fusarium spp.; PITT \& HOCKING, 1997 para Penicillium spp.; KLICH, 2002 para Aspergillus spp.).

A detecção, quantificação e triagem de AFLs, OTA, FB1 e ZEA foi realizada através de técnica de ELISAespecífica (ROMERLABS ${ }^{\circledR}$, 2014). As amostras positivas foram quantificadas através cromatografia líquida de alta eficiência (CLAE), de acordo com a técnica proposta por Soares e Rodriguez-Amaya (1989).

\section{Resultados e Discussão}

Os valores máximos e mínimos das contagens fúngicas observados no estudo estão apresentados na tabela a seguir:

Tabela 1: Contagem total (log/UFC) para fungos filamentosos (DRBC), fungos xerofílicos (DG18) e Fusarium (DCPA) em rações para pássaros ornamentais

\begin{tabular}{cccc}
\hline Amostras & Mínimo & Máximo & Média \\
\hline DRBC & 4,10 & 6,25 & $5,20 \pm 5,55$ \\
DG18 & 5,50 & 6,05 & $5,95 \pm 5,50$ \\
DCPA & 1,35 & 2,00 & $1.95 \pm 1,20$ \\
\hline
\end{tabular}

Com base nos dados apresentados, as amostras apresentaram contagens com valores bem distintos entre seus valores máximos e mínimos, fato evidenciado através das médias e do desvio padrão das análises. Segundo o GMP+ Certification Scheme Animal Feed Sector (2006), o limite de unidade formadora de colônia (UFC) estipulado para a garantia de higiene em rações é de $1.0 \times 10^{4} \mathrm{UFC} / \mathrm{g}$ e, dentre as amostras analisadas, apenas a contagem de Fusarium spp. manteve-se dentro do limite preconizado. Os resultados encontrados são sugestivos de uma atividade fúngica elevada, o que pode afetar a palatabilidade da ração e ainda reduzir a absorção de nutrientes pelo animal. $A$ porcentagem das amostras acima do limite determinado pode ser atribuída à falta de um controle antifúngico adequado. De maneira geral, isso pode ocorrer por conta das matérias primas comercializadas com destino à alimentação animal que, muitas vezes, são de qualidade inferior (QUEIROZ et al., 2013).

A qualidade das matérias primas que são utilizadas no processo de produção de rações deve ser controlada, já que fungos xerofílicos conhecidamente crescem em ambientes de baixa atividade de água (PITT, 1998). O armazenamento correto das rações tem influência sobre o crescimento fúngico, deve ser levanda em consideração a umidade no ambiente para evitar que a ração absorva água. Outro fator a ser considerado é a produção de conídios devido a sua importância na resistência e crescimento fúngico (FAO, 2006). Assim, considera-se que a micobiota isolada é proveniente da própria amostra analisada.

Dentre os fungos xerofílicos, destacam-se o grupo dos xerofílicos moderados que possuem capacidade de crescer em meios com baixa atividade de água e sem necessidade de meios específicos para o crescimento. Nesse grupo destacam-se espécies dos gêneros Aspergillus e Penicillium (SAMSON, 2000), sendo o gênero Aspergillus spp. o que 
se mostrou mais prevalente na micobiota após a análise de prevalência, ocorrendo em 95 e $88 \%$ das amostras de rações. O Cladosporium spp. apresentou $73 \%$, seguido por Penicillium spp. A identificação dessas colônias encontradas é um indicativo de um controle antifúngico ineficaz como evidenciado por Quadros et al (2009) em seus trabalhos.

O estudo indica a ocorrência de micotoxinas dos grupos das aflatoxinas (AFLs), fumonisinas $\left(F_{1}\right.$ ) e zearalenona (ZEA). Os níveis de AFLs não diferiram entre marcas comerciais de ração, variando de $2,2 \mu \mathrm{g} / \mathrm{kg}$ a $34,0 \mu \mathrm{g} / \mathrm{kg}$. Segundo legislação brasileira, os níveis de alflatoxina se mantiveram abaixo do limite máximo de $50 \mu \mathrm{g} / \mathrm{kg}$ preconizado (BRASIL, 1988). Os níveis de $F^{1}$ e de ZEA variaram de $2,2 \mu \mathrm{g} / \mathrm{kg}$ a $34,0 \mu \mathrm{g} / \mathrm{kg}$ e $1,73 \mathrm{ng} / \mathrm{kg}$ a $404,0 \mathrm{ng} / \mathrm{kg}$, respectivamente. De acordo com a comissão europeia, a contaminação por fumonizinas foi abaixo do nível permitido de até $5 \mu \mathrm{g} / \mathrm{kg}$ em rações destinadas para animais (CE, 2006), bem como o nível de ZEA, cujo limite estipulado para alimentação animal é de $0,5 \mu \mathrm{g} / \mathrm{kg}$ (CE, 2003).

A presença de fumonisinas assim como aflatoxinas é alarmante, já que essas substâncias podem interagir e induzir a formação de câncer de fígado em outros animais (Gelderblom et al. 2002), entretanto não existem estudos que confirmem ao descartem o efeito dessa interação em psitacídeos e passeriformes. Em estudos realizados com galinhas (Kubena et al. 1995), foi observado um efeito aditivo dessas micotoxinas.

\section{Referências}

BRAGULAT, M.R et al. An easy screening method for fungi producing ochratoxin A in pure culture. International Journal of Food Microbiology, v. 71, n.3, p. 139-144, 2001.

BRASIL. Ministério Agricultura, Pecuária e Abastecimento. Portaria no 07 de 09 de novembro de 1988.

Diário Oficial [da] União, Brasília, DF, 14 de novembro de 1988. Seção 1.

CE. COMUNIDADE EUROPÉIA. Regulamento N 576/2006 de 15 de Novembro de 2006, relativo a critérios microbiológicos aplicáveis aos gêneros alimentícios. Journal Oficial da União Européia, 16 de agosto de 2006.

CE. COMUNIDADE EUROPÉIA. Regulamento No 100/2003 de 31 de Outubro de 2003, relativo a critérios microbiológicos aplicáveis aos gêneros alimentícios. Journal Oficial da União Européia, 2003.

FAO - FOOD AND AGRICULTURY ORGANIZACION. Pan-European Conference on Food Safety and Quality 2003. A compendium: FAO Veterinary Public Health and Food and Feed Safety Programme: the Safety of Animal Products from Farm to Fork, 2007.

GMP + Certification Scheme Animal Feed Sector. 2006. Appendix 1: Product standards (including residue standards). The Hague, the Netherlands: Products chap Diervoeder. p. 1 - 39. 2008.

KELLER, K. M. et al. Effect of yeast cell wall on the performance of broiler chickens intoxicated with aflatoxin B1. Revista Brasileira de Medicina Veterinária, v. 34, n. 2, p. 101-105, 2012.

KELLER, L. A. M. et al. Fungal and mycotoxins contamination in corn silage: Monitoring risk before and after fermentation. Journal of Stored Products Research, v. 52, p. 42-47, 2013.

$\mathrm{KLICH}, \mathrm{M} . \mathrm{A}$. Identification of common Aspergillus species. Netherlands: Central bureau voor Schinmelcultures, 2002. 116p.
Ainda que os níveis de micotoxinas encontrados estejam abaixo dos níveis preconizados, o impacto na saúde de aves ornamentais, assim como, a perda econômica com medicamentos e assistência veterinária, fazem com que seja necessária a existência de leis e controle mais efetivos. $O$ principal foco da regulação de micotoxinas em rações animais é voltado para a produção de rebanhos e pecuária, pouca atenção é dada a alimentação de animais domésticos. Tanto padrões europeus quanto as leis brasileiras são destinadas a animais de produção, assim, a aplicabilidade dessas normas na criação de aves ornamentas é discutível, já que se fazem necessários mais estudos.

\section{Conclusões}

As amostras avaliadas apresentaram não conformidade quando confrontada com os padrões de qualidade internacionais em relação a contagem fúngica. Já os níveis de micotoxinas estão em conformidade com as normas internacionais. Entretanto, não existe, até o momento, padrões estabelecidos para presença de micotoxinas em rações destinadas a aves ornamentais. Em vista de minimizar a contaminação fúngica e, considerando que a matéria prima é fonte primária de contaminantes fúngicos, assim como da umidade, é possível sugerir um controle rigoroso da matéria prima da qual a ração é preparada como alternativa para minimizar a contaminação por fungos e suas micotoxinas.

LEITAO, D. F. G. M. et al. Effectiveness of Additives Based on Yeast Cell Wall In Diets of Gilts Intoxicated by Zearalenone. Veterinaria e Zootecnia, v. 23, n. 4, p. 696-706, 2016.

IARC - INTERNATIONAL AGENCY FOR RESEARCH ON CANCER. Evaluation of carcinogenic risks to humans: some naturally occurring substances; food items and constituents, heterocyclic aromatic amines and mycotoxins. Lyon: IARC, v. 56, p. 489-521, 1993. Monographs on the Evaluation of Carcinogenic Risks to Humans.

MALLOZZI, A.B.; CORRÊA, B. Fungos Toxigênicos e Micotoxinas. Boletim Técnico do Instituto Biológico, São Paulo, n.12, p.5-26, 1998.

MARTH, E. H. Mycotoxins: production and control. Food Laboratory News, v. 8, n. 3, p. 35-51. 1992.

NELSON, P.T.; TOUSSOIN, T.A.A.; MARASAS, W.E.O. Fusarium species: An illustrated manual for identification. London: The Pennsylvania State University Press, 1983.

PITT, J. L.; HOCKING, A.D. Fungi and food. London: Black Academia \& Professional Chapmam \& Hall, 1997. 593p.

QUEIROZ et al. Fungal contamination and determination of fumonisins and aflatoxins in commercial feeds intended for ornamental birds in Rio de Janeiro, Brazil. Letters in Applied Microbiology, 2013.

SAMSON, R. A.; VAN REENEN-HOEKSTRA, E. S.; FRISVAD, J. C.; FILTENBORG, O. Introduction to Food and Airborne Fungi. 6 ed. Netherlands: Centraal bureau Voor Schimmelcultures, 2000. 388 p.

SOARES, L.M.V.; RODRIGUES-AMAYA, D. Survey of Aflatoxins, Ochratoxin A, Zearalenone, and Sterigmatocystin in some Braziliam Foods by using Multi-toxin Thin-Layer Chromatographic Method. Journal - AOAC - Association of Official Analytical Chemists, v. 72, n. 1, p. 22-26, 1989.

SCUSSEL, V.M. Micotoxinas em alimentos. Florianópolis: Insular, 1988. p.19-22. WATSON, D.H. Natural toxicants in food. Chichester: Ellis Horwood, 1987. p.232-247. 